Published in final edited form as:

J Control Release. 2018 March 10; 273: 139-146. doi:10.1016/j.jconrel.2018.01.010.

\title{
Delivery of Lethal dsRNAs in Insect Diets by Branched Amphiphilic Peptide Capsules.
}

\author{
L.A. Avila ${ }^{1,2, \dagger,}{ }^{*}$, R. Chandrasekar ${ }^{2, \dagger}$, K.E. Wilkinson ${ }^{2}$, J. Balthazor ${ }^{2,3}$, M. Heerman $^{2}$, J. \\ Bechard $^{2}$, S Brown ${ }^{4}$, Y. Park ${ }^{5}$, S. Dhar6, G.R. Reeck ${ }^{2}$, J.M. Tomich ${ }^{2}$ \\ 1 Department of Chemistry and Biochemistry, Auburn University, Auburn, AL 36849, USA. \\ ${ }^{2}$ Department of Biochemistry \& Molecular Biophysics, Kansas State University, Manhattan, KS \\ 66506-3902, USA. \\ ${ }^{3}$ Department of Chemistry, Fort Hays State University, Hays, KS 67601-4099, USA. \\ ${ }^{4}$ Division of Biology, Kansas State University, Manhattan, KS 66506-3902, USA. \\ ${ }^{5}$ Department of Entomology, Kansas State University, Manhattan, Kansas 66506-4004, USA. \\ ${ }^{6}$ Department of Physics, Auburn University, Auburn, AL 36849, USA.
}

\begin{abstract}
Development of new and specific insect pest management methods is critical for overcoming pesticide resistance and collateral off-target killings. Gene silencing by feeding dsRNA to insects shows promise in this area. Here we described the use of an all peptide nano-material, Branched Amphiphilic Peptide Capsules (BAPCs), that facilitates cellular uptake of dsRNA by insects through feeding. The insect diets included dsRNA with and without complexation with BAPCs. The selected insect species come from two different Orders with different feeding mechanisms: Tribolium castaneum and Acyrthosiphon pisum. The gene transcripts tested (BiP and Armet) are part of the unfolded protein response (UPR) and suppressing their translation resulted in lethality. For Acyrthosiphon pisum, ingestion of BiP-dsRNA associated with BAPCs led to the premature death of the aphids ( $\mathrm{t}_{1 / 2}=4-5$ days) compared to ingestion of the same amounts of free BiPdsRNA ( $\mathrm{t}_{1 / 2}=11-12$ days). Tribolium castaneum was effectively killed using a combination of BiP-dsRNA and Armet-dsRNA complexed with BAPCs; most dying as larvae or during eclosion $(\sim 75 \%)$. Feeding dsRNA alone resulted in fewer deaths $(\sim 30 \%)$. The results show that complexation of dsRNA with BAPCs enhanced the oral delivery of dsRNA over dsRNA alone.
\end{abstract}

\section{Keywords}

BAPCs; dsRNA; Oral Delivery; Tribolium castaneum; Acyrthosiphon pisum; Armet; BiP

\footnotetext{
"Corresponding author address: laa0029@auburn.edu (LA Avila).

$\dagger$ These authors contributed equally to this work.
} 


\section{INTRODUCTION}

We recently described a new class of nanomaterials made of branched amphiphilic peptide capsules (BAPCs) ${ }^{1}$. These nanocapsules have unusual but highly desirable properties that address some of the shortcomings associated with other nanoparticles ${ }^{2}$. For instance, they are water soluble, stable in blood and made entirely of natural amino acids ${ }^{3}$. They display sizes (depending on annealing conditions), ranging from 10-50 nm and are resistant to detergents, proteases and chaotropes ${ }^{4,5,6}$. The BAPCs used in this study are composed of an equimolar mixture of two branched peptides: bis(Ac-FLIVIGSII)-K-K $\mathrm{K}_{4}-\mathrm{CO}-\mathrm{NH}_{2}$ and bis(Ac-FLIVI)-K- $\mathrm{K}_{4}-\mathrm{CO}-\mathrm{NH}_{2}$ and originate from the one of the pore-forming segments of human heart L-type dihydropyridine sensitive calcium channel ${ }^{1}$. These nanocapsules show promise as an alternative non-viral nucleic acid delivery vector, for both in vitro and in vivo systems ${ }^{3}$. In vitro, DNA-BAPCs nanoparticles have been used to transfect several cells lines including, HEK, HeLa and murine dendritic cells, with a higher transfection efficiency than that observed with a popular lipid-based commercial product and with negligible cytotoxicity ${ }^{3}$. In vivo, BAPCs were capable of delivering a vaccine DNA encoding the E7 oncoprotein of HPV-16 (pgDE7) in mice. Mice immunized with pgDE7-BAPC nanocapsules complexes constrained tumor growth up to one month after transplantation of tumor cells without significant toxic effects ${ }^{3}$. Investigation of the physical BAPC/DNA interactions, based on two different imaging techniques, revealed compact clusters ranging in average size from 50 to $250 \mathrm{~nm}^{3}$. Comparable to histone compaction of DNA to form nucleosomes, the $20-30 \mathrm{~nm}$ BAPCs interact with plasmid DNA, acting as cationic nucleation centers with the negatively charged DNA binding to the outer surface ${ }^{3}$. These results indicated that BAPCs facilitate the uptake of plasmid DNA and potentially other types of nucleic acids such as small oligonucleotides or RNAs.

Entry of dsRNA into cells is the first step in one of the most useful tools in contemporary molecular biology: transcript knockdown via $\mathrm{RNAi}^{7,8}$. RNAi-based transcript knockdown has been used in insects of numerous Orders and is a key part of the reverse-genetics toolbox in insects ${ }^{9}$. The dsRNA constructs have been administered primarily to insects by microinjection into hemolymph ${ }^{10}$. While effective, injection has its limitations, which include the tedium of treating numerous insects and the difficulties in injecting smaller insect species (or earlier stages of development). Along with injections, methods such as soaking ${ }^{11}$ and ingestion have been explored but with limited success and reproducibility. Recently, a few studies have shown that ingestion of dsRNA associated with nanomaterials can enhance silencing activity ${ }^{12,13,14}$. Positive results have been observed forming complexes of dsRNA with cationic lipids ${ }^{13}$ and modified polysaccharides such as chitosan ${ }^{12}$. However, despite this progress, the RNAi effects are low and highly variable. The consensus in the field, drawn largely from unsuccessful and therefore unpublished studies, is that the feeding of dsRNA to insects is at best inefficient and at worst entirely ineffectual ${ }^{8}$.

In this study, BAPCs were tested for their ability to facilitate uptake of dsRNA by insects through feeding to enhance transcript knockdown. The insect diets included dsRNA with and without complexation with BAPCs. The selected insect species come from different Orders and with different feeding mechanisms: Tribolium castaneum, the red flour beetle 
was fed an amended solid flour diet ${ }^{15}$; and the pea aphid, Acyrthosiphon pisum, was fed an artificial liquid diet ${ }^{16}$. The genomic sequences for both insects are published. Tribolium is a major genetic model and a species in which transcript knockdown via dsRNA injection is perhaps more effective than in any other insect species ${ }^{17}$. It is moreover a model organism relevant to biochemical and cell biological processes in humans ${ }^{17}$. As a major target in both species, we chose the transcript of BiP (GRP78). Its activity is importance in the unfolded protein response (UPR) ${ }^{18}$. For Tribolium we included the transcript of another UPR member, Armet (also known as MANF) ${ }^{19}$. In a separate experiment in Tribolium, we knocked down the Vermillion transcript, as an example of a transcript that is in a wholly internal organ (in contrast to the gut, a probable site of action in the knockdown of the BiP and Armet transcripts). Vermillion encodes the enzyme tryptophan oxidase, required for brown eye pigment synthesis in Tribolium ${ }^{20}$. Feeding of BAPCs-Vermillion-dsRNA complexes resulted in the absence of dark pigmented eye color in treated insects. In a separate experiment, fluorescently labeled dsRNA was located in the internal organs of dissected adult Tribolium after treatment with the BAPC/dsRNA complexes.

RNAi technology has tremendous potential in eliminating disease-carrying or pest insects but further experimentation is required to identify suitable gene targets in accessible cellular targets using a method that can be easily scaled. The bio-based capsules described in this report facilitate the in vivo oral delivery of dsRNAs with high efficiency and low cytotoxicity (nano-capsules alone) in the systems tried to date. The self-assembling peptides that form the capsules are easily synthesized with high purity, assemble in pure water and can be stored dry for extended periods prior to rehydration in the presence of dsDNA or dsRNA. The synthesis of these peptides is easily scaled to the multi-gram level, and with low $\mu \mathrm{M}$ concentrations required per treatment, the cost of using these carriers should make this tool readily available to any researcher for potential applications to control pests in high value situations.

\section{MATERIALS AND METHODS}

\section{Peptide synthesis}

The branched amphiphilic peptides bis(Ac-FLIVIGSII)-K-K $\mathrm{K}_{4}-\mathrm{CO}-\mathrm{NH}_{2}$ and bis(Ac-FLIVI)$\mathrm{K}-\mathrm{K}_{4}-\mathrm{CO}-\mathrm{NH}_{2}$, were synthesized and cleaved as previously described ${ }^{1}$. The cleaved peptides were washed three times with diethyl ether, dissolved in water, and lyophilized before storage at RT. The peptides were purified by reversed phase HPLC and characterized using matrix-assisted laser desorption/ionization-time of light (MALDI TOF/TOF).

\section{BAPC's preparation}

The peptides, bis(Ac-FLIVIGSII)-K-K ${ }_{4}-\mathrm{CO}-\mathrm{NH}_{2}$ and bis(Ac-FLIVI)-K- $\mathrm{K}_{4}-\mathrm{CO}-\mathrm{NH}_{2}$, were individually dissolved in pure 2,2,2-Triuoroethanol (TFE) and mixed together in an equimolar ratio in at $1 \mathrm{mM}$ final concentration. Peptide concentrations were calculated using the molar absorptivity (ع) of phenylalanine in water at $257.5 \mathrm{~nm}\left(195 \mathrm{~cm}^{-1} \mathrm{M}^{-1}\right)$. After mixing they were allowed to stand for 10 minutes before removing the solvent under vacuum. $1 \mathrm{~mL}$ of water was added drop-wise into the dried peptide mixture and allowed to sit for $30 \mathrm{~min}$ at $25^{\circ} \mathrm{C}$ to form capsules at $1 \mathrm{mM}$ final concentration. Subsequently, the 
capsule containing solution was incubated for $1 \mathrm{~h}$ at $4^{\circ} \mathrm{C}$ to prevent capsule fusion ${ }^{4}$. After 1 $\mathrm{h}$, the peptide sample was returned to $25^{\circ} \mathrm{C}$ for $30 \mathrm{~min}$ before drying for log-term storage or mixing with the dsRNA.

\section{Preparation of dsRNA-BAPC's nanoparticles}

To treat 10 Tribolium castaneum beetles, $200 \mu \mathrm{L}$ water solutions containing $10 \mu \mathrm{g}$ of Tribolium dsRNA of Armet, BiP or Vermilion separately or Armet and BiP together, were added drop-wise to $200 \mu \mathrm{L}$ solutions containing $400 \mu \mathrm{M}$ BAPCs. For the group treated with a combination of BiP-dsRNA and Armet-dsRNA, we added $5 \mu \mathrm{g}$ of each and mixed it with $200 \mu \mathrm{L}$ of BAPCs at $400 \mu \mathrm{M}$. Solutions were mixed carefully by pipette and allow to stand for $10 \mathrm{~min}$ before adding $\mathrm{CaCl}_{2}$ at that yielded $1.0 \mathrm{mM}$ final concentration. After $30 \mathrm{~min}$ incubation, the solutions were mixed with the insect diet.

To treat 5 Acyrthosiphon pisum pea aphids, $0.1 \mu \mathrm{g}$ of Acyrthosiphon pisum BiP-dsRNA was dissolved in $10 \mu \mathrm{L}$ of water. Subsequently, the solution was added drop-wise into a $10 \mu \mathrm{L}$ solution containing BAPCs at $200 \mu \mathrm{M}$. Solutions were mixed carefully with pipette and allow to stand for $10 \mathrm{~min}$ before adding $\mathrm{CaCl}_{2}$ yielding $1.0 \mathrm{mM}$ final concentration. After another $10 \mathrm{~min}$ incubation period, sucrose $(500 \mathrm{mM})$ was added. For the insects treated with lesser amounts of BiP-dsRNA, BAPC/nucleotide complexes prepared as above were diluted $10 \mathrm{x}$ and $100 \mathrm{x}$ with water prior to adding the $\mathrm{CaCl}_{2}$.

\section{Dynamic light scattering (DLS) and zeta potential (ZP)}

The different dsRNA-BAPCs formulations were prepared as previously described (Preparation of dsRNA-BAPC's nanoparticles). The particle sizes and zeta-potentials for all samples were determined using a Zetasizer Nano ZS (Malvern Instruments Ltd, Westborough, MA). Samples were analyzed in $\mathrm{CaCl}_{2}(2 \mathrm{mM})$ and all measurements were performed in triplicates.

\section{Atomic Force Microscopy}

The dsRNA-BAPCs complexes were prepared as previously described and deposited onto silicon substrates with native oxide. Topographical images were obtained using a ParkXE7 AFM from Park Systems (Korea) in non-contact mode, using a silicon cantilever (Park Systems, PPP-NCHR) with a nominal tip diameter of $14 \mathrm{~nm}$ and nominal of spring constant $42 \mathrm{~N} / \mathrm{m}$. The silicon substrates had a thin layer of native oxide $(\sim 1-2 \mathrm{~nm})$ on the surface (HF/BOE etching was not performed).

\section{Insects}

Acyrthosiphon pisum (pea aphid) were maintained in cages on Vicia faba (broad Windsor) plants according to Mutti et al., $2008^{21}$. All feeding trial bioassays were conducted at $22{ }^{\circ} \mathrm{C}$ and programmed for a cycle of $16 \mathrm{~h}$ of light and $8 \mathrm{~h}$ of darkness. Tribolium castaneum (GA-1 strain) insects were reared at $30{ }^{\circ} \mathrm{C}$ on wheat flour containing $5 \%$ brewer's yeast under the standard conditions as described previously ${ }^{22,23}$. 


\section{Diet containing ds-RNA-BAPC's nanoparticles (Tribolium castaneum)}

Media to feed 10 insects was prepared by mixing $70 \mathrm{mg}$ Golden Buffalo Flour (Heartland Mill, Inc. Marienthal, KS) with $400 \mu \mathrm{L}$ of dsRNA-BAPC's complexes prepared as previously described. The flour and the dsRNA-BAPCs solution was mixed by inversion several times. This mixture was held under vacuum for approximately $10 \mathrm{~h}$. When the mixture was complete dry, we distributed it into a 96-well plate, adding around $7 \mathrm{mg}$ per well. Immediately, we placed one insect per well (in larvae and/or pre-pupae stage (mass around $2 \mathrm{mg}$ ). For the control group containing only dsRNA, we mixed $70 \mathrm{mg}$ Golden Buffalo Flour with $10 \mu \mathrm{g}$ of either Armet-, BiP- or Vermilion-dsRNAs dissolved in $400 \mu \mathrm{L}$ of water and $160 \mathrm{mM} \mathrm{CaCl}_{2}$. Other controls were prepared by just mixing $70 \mathrm{mg}$ of flour with $400 \mu \mathrm{L}$ of water plus and minus BAPCs $(40 \mu \mathrm{M})$. We analyzed a total of 30-35 animals per group. Animals were kept at $30^{\circ} \mathrm{C}$ for the indicated periods with visual monitoring of phenotypes and for mortality.

\section{Diet containing ds-RNA-BAPC's nanoparticles (Acyrthosiphon pisum)}

For control samples the aphids were placed on petri dishes containing sterilized $2 \%$ agar (supplemented with $0.1 \%$ Miracle grow fertilizer and $0.03 \%$ methyl 4-hydroxybenzoate) healthy leaf (fava beans) was inserted and feeding was carried out $48 \mathrm{~h}^{24}$. For the dsRNA feeding trial up to five adult aphids (without over-crowding) were transferred with a fine paintbrush onto a feeding sterile plastic cup (Falcon, Primaria, NJ, USA). A layer of stretched parafilm (Fisher scientific, USA) was placed over plastic cups containing the 5 insects per cup. The artificial diet $(20 \mu \mathrm{L})$ containing free- or BAPC-conjugated BiP-dsRNA was placed on top of parafilm stretched over the cup. A second layer of stretched parafilm was placed on top of the diet thus forming a pocket. The aphids fed on the diet by penetrating the bottom layer of parafilm. Three different concentration of dsRNA were used $0.1 \mu \mathrm{g}, 0.01 \mu \mathrm{g}$ and $0.001 \mu \mathrm{g}$ containing $12.5 \mathrm{mM} \mathrm{CaCl}_{2}$. Aphids were allowed to feed on the diet for $48 \mathrm{hr}$. Then the aphids were transferred to plant leaves prepared as previously mentioned for the control group. In each experiment, three replicates were included in the artificial diet feeding. Survival assays were conducted separately using $10 \times 3$ aphids per group in each feeding experiment. Each experimental group was monitored daily to record and remove dead adult aphids and nymphs.

\section{RNA extraction and cDNA synthesis}

Adult aphids (10 insects) were homogenized with a polypropylene pestle in $1 \mathrm{~mL}$ of TRIZOL reagent according to the protocol supplied by the manufacturer (Invitrogen, CA, USA) to extract the RNA. DNA contamination in the dsRNA samples was minimized by treating the RNA fraction following the protocol provided in the TURBO DNA-free kit (Ambion, Austin, TX, USA). RNA (4 $\mu \mathrm{g}$ of DNA-free) was reverse-transcribed into complementary DNA (cDNA) using the SuperScript III First Strand Synthesis System for RT-PCR (Invitrogen, CA, USA). A similar procedure was applied for Tribolium larvae (7 insects). 


\section{dsRNA synthesis}

The nucleotide sequences of target genes from both insects (pea aphid: p-BiP: NCBI Accession No. XM_003244000.1); Tribolium castaneum: TcBiP: XM_015982882.1; TcArmet: XM_966545.3; TcVer: NM_001039410) were obtained from the NCBI database. Gene-specific primers, including the T7 polymerase promoter sequences at the 5' end, were used to synthesize dsRNA from respective insects (see Table 1 Supplementary Data) using the AmpliScribeTM T7 Flash Transcription Kit protocol (Cat. No. ASF3507, Epicentre Biotechnologies, USA). PCR products were separated on $1.4 \%$ agarose gels prepared in 40 $\mathrm{mM}$ Tris-acetate $(\mathrm{pH} 8.3)$ and $1 \mathrm{mM}$ EDTA. Ethidium bromide was added to a final concentration of $0.7 \mu \mathrm{g} / \mathrm{mL}$ before allowing the agarose to solidify. The gels were photographed under UV light and images were captured by gel documentation (UVP-Digital Imaging System, Upland, CA, USA).

\section{Fluorescence Labeling of Armet-dsRNA}

A thiol functional group was introduced at the 5' ends of the unmodified Armet-dsRNA. A 5' OEndTAg Nucleic Acid Labeling Kit (Vector Laboratories, USA) was used for the incorporation of the thiol functional group. Subsequently, we incorporated the thiol-reactive fluorescence label Atto633-Maleimide (Atto-Tec GmbH, Germany). Briefly, $0.4 \mathrm{nmol}$ of Armet-dsRNA was incubated at $37{ }^{\circ} \mathrm{C}$ for $30 \mathrm{~min}$. with ATP $\Upsilon S$ and T4 polynucleotide kinase (T4-PNK). A thiophosphate is transferred from ATPrS to the 5' hydroxyl groups of a double stranded nucleic acid by T4-PNK. Next, the Atto633-Maleimide dye was added in 3 molar excess and incubated at room temperature for 3 hours keeping the $\mathrm{pH}=8$ to ensure deprotonation of the thiol group. After this incubation period, the dsRNA was isolated using buffered phenol. Upon completion of purification the concentration was read using the Nano drop method and labeling was confirmed by fluorescence measurements.

For the diet preparations, the fluorescence labeled Armet-dsRNA was mixed with BAPCs following the protocol previously described. Next, $400 \mu \mathrm{L}(10 \mu \mathrm{g})$ of the labeled ArmetdsRNAs, free or complexed with BAPCs, were mixed with $100 \mathrm{mg}$ of flour. These mixtures were held under vacuum for approximately $10 \mathrm{~h}$. When the two mixtures were complete dry they were distributed into a 96-well plate, adding $10 \mathrm{mg}$ per well to treat Tribolium castaneum 10 larva. An additional control groups containing the diet with only water was included for comparison purposes.

\section{Confocal Laser Scanning Microscopy Analysis}

Insects were harvested at $24 \mathrm{~h}$ and $48 \mathrm{~h}$ post feeding with the larva Tribolium castaneum beetles were dissected for visualization of the organs in PBS and fixed in in $4 \%$ formalin. The images shown in Fig. 7 was captured using a confocal LSM 700 laser-scanning microscope (Carl Zeiss, Gottingen, Germany) using a $639 \mathrm{~nm}$ laser.

\section{Quantification of BiP by RT-PCR}

For days 1-8, gut tissues were collected each morning from BAPC-conjugated BiP-dsRNA treated and untreated pea aphids ( 20 insects/group). RNA was isolated from collected gut tissues as per the protocol described previously. RT-PCR was performed with gene specific primers for $\mathrm{p}-\mathrm{BiP}$ gene. Each reaction contained $1 \mu \mathrm{L}$ of cDNA, $1 \mu \mathrm{L}$ of the specific primers 
(10 pmol $/ \mu \mathrm{L}$ ), and $10 \mu \mathrm{L}$ of $2 \times$ SYBR Green Super-mix reagent (Bio-Rad) in a final volume of $20 \mu \mathrm{L}$. The following PCR program was used for all PCR reactions: $90{ }^{\circ} \mathrm{C}$ for $3 \mathrm{~min}$, followed by 40 cycles of $95^{\circ} \mathrm{C}$ for $30 \mathrm{~s}, 55^{\circ} \mathrm{C}$ for $30 \mathrm{~s}, 72^{\circ} \mathrm{C}$ for $30 \mathrm{~s}$ followed by $10 \mathrm{~min}$ at $72^{\circ} \mathrm{C}$ at the end. Threshold Cycle (CT) values were calculated using Bio-Rad CFX Manager ${ }^{\mathrm{TM}}$ software (Bio-Rad). The Ct values were normalized with pea aphid using RpL27 primer (Forward: TCGTTACCCTCGGAAAGTC; Reverse: GTTGGCATAAGGTGGTTGT) as reference gene for equal cDNA template amounts. Fold changes were calculated by comparing the normalized transcript level of free BiP-dsRNA treated samples to the BiPdsRNA/BAPC treated group.

\section{Statistical analyses}

Statistics were performed using GraphPad Prism 5 software (GraphPad Software, La Jolla, CA). Statistical significance for DLS and ZP experiments was determined using ANOVA test followed by Bonferroni's post-test. For survival studies the Log-rank (Mentel-Cox) test was used.

\section{RESULTS AND DISCUSSION}

\section{Biophysical Characterization of the BAPCs-dsRNA particles}

BAPCs were prepared by mixing the two peptides, bis(Ac-FLIVIGSII)-K- $\mathrm{K}_{4}-\mathrm{CO}-\mathrm{NH}_{2}$ and bis(Ac-FLIVI)-K- $\mathrm{K}_{4}-\mathrm{CO}-\mathrm{NH}_{2}$, at equimolar concentration in 2,2,2, Trifluoroethanol (TFE). The solvent was removed under vacuum and subsequently water was added drop wise until reaching the desired concentration. The newly formed capsules were subjected to different temperature shifts to fix their size $(20-30 \mathrm{~nm})^{4}$. Nanocapsules prepared in this fashion are said to be "conformationally constrained" because their size is unaffected by solvents or chaotropes ${ }^{5}$. The capsule formation mechanism initiates with the supramolecular selfassembly of the hydrophobic segments that initially drive the formation of an ordered bilayer delimited, spherical water-filled structures. The positively charged lysines face the two aqueous phases, and the hydrophobic residues stabilizing the structure as extended strands with inter- and intra-molecular hydrogen bonds ${ }^{1}$. We hypothesized that dsRNA interacts with the cationic surface of this "conformationally constrained" BAPCs by coating the surface, perhaps through winding, similar to the way that BAPCs interact with plasmid $\mathrm{DNA}^{3}$. Atomic force microscopy (AFM) images of the BAPCs-RNAi complexes showed compact dry clusters ranging from 70 to $500 \mathrm{~nm}$ (Figure 1B). According with the topography, it appears that most of clusters involve the recruitment of several BAPCs forming assemblies with different shapes and morphologies. Figure 1C shows a schematic representation of the potential interactions between dsRNA and BAPCs. AFM analysis of only BAPCs (Figure 1B) confirm the structure of single capsules with a size ranging from 25 to $100 \mathrm{~nm}$. A silicon sample with only water was also analyzed for comparative purposes to ensure a flat surface (image not shown).

To explore additional biophysical features of the BAPCs-dsRNA we performed a Dynamic Light Scattering (DLS) and Zeta Potential analyses. Different formulations were tested keeping the amount of dsRNA constant $(1 \mu \mathrm{g})$ and varying the BAPCs concentration. Sizes ranging from 70 to $300 \mathrm{~nm}$ were observed by DLS, results that are in accordance with the 
particle sizes observed in AFM (Figure 2A). Similar sizes were observed for the formulations containing lesser amounts of dsRNA (Supplementary Data Figure 1) indicating that the complexes are tightly bound as they do not readily dissociate upon dilution.

The complexes increased in size at high concentrations of the BAPCs suggesting that when the particles are in excess of the nucleic acid the dsRNAs straddle multiple BAPCs thereby generating larger oligomeric states.

The zeta potentials (ZP) of the nanostructures were determined at several BAPC to dsRNA ratios (Figure 2B and Supplementary Data Figure 1). The ZP can be defined as the charge that develops at the interface between a solid surface and its liquid medium ${ }^{25}$. Positive ZP's enhance the interaction with cell membranes however, values above $45 \mathrm{mV}$ can be toxic. Particles with negative ZP do not interact efficiently with the negatively charge cell surface $^{26}$. The surface charges for the different dsRNA-BAPCs complexes ranged from, 10 to $28 \mathrm{mV}$. These results appeared to be suitable for generating strong interactions with the negatively cell membrane surfaces but not so high as to trigger cell damage. We believe that even if the dsRNA surrounds the peptides capsules, such that there are a sufficient number of positives charges remaining on the capsule surface thus retaining a positive zeta potential.

\section{BAPCs deliver a lethal dsRNA added to the artificial liquid diet of the pea aphid}

The pea aphid (Acyrthosiphon pisum) is currently the model organism among aphids, with a sequenced genome ${ }^{15}$ and many Expressed Sequence Tags (ESTs), deposited at AphidBase.com. In the pea aphid, transcript knockdowns via RNAi have been reported by others and us, with most of them relying on microinjection into the hemolymph ${ }^{8,20}$.

The pea aphid is commonly maintained in the laboratory on fava bean plants but it also does well on appropriate artificial liquid diets and the life span of an adult is about 20-30 days $^{23,27}$. We tested the ability of dsRNA/BAPC complexes to effectively deliver dsRNA to the pea aphid their suspended in liquid diet.

In Figure 3A we show survival curves for pea aphids that ingested dsRNA/BAPC complexes added to a standard artificial liquid diet (for $48 \mathrm{~h}$ ) before being transferred to fava bean leaves. Mortality was monitored daily. Incubation of 5 insects with diets containing 10 or $100 \mathrm{ng}$ of BiP-dsRNA (in the form of dsRNA/BAPCs complexes) led to the premature death of the aphids ( $\mathrm{t}_{1 / 2}=4-5$ days) compared to ingestion of the same amounts of free BiPdsRNA ( $t_{1 / 2}=11-13$ days). It should be noted that the actual amounts of dsRNA/BAPC complexes ingested by an individual insect would be less than the total added to the shared diet. Feeding a diet containing just $1 \mathrm{ng}$ of the dsRNA/BAPC complex had no effect. This shows that concentrations greater than $10 \mathrm{ng}$ are in excess of that required for the biological effect observed.

Ingestion of free dsRNA gave slightly earlier deaths, and the survival curve for insects that had ingested diet supplemented with only BAPCs was not statistically different from that for aphids that ingested normal diet with no additions (Figure 3B). We tested four different BAPC concentrations with 100 ng dsRNA: 10, 2040 and $100 \mu \mathrm{M}$ (data not shown), with the $40 \mu \mathrm{M}$ complex showing the highest inhibitory effect. 
In insects that had ingested the dsRNA/BAPC complexes, the BiP transcript level in the aphids' guts fell dramatically (Figure 4). The time course for the decrease in BiP transcriptlevel, preceded the survival curve of the aphids. The BiP transcript level did not change significantly when aphids ingested just free dsRNA added to their diet (Figure 4).

Our experiments with the pea aphid indicate that BAPCs very effectively deliver dsRNA from artificial liquid diet, markedly increasing the efficiency of RNAi-based knockdown of a transcript that encodes a vitally important protein.

\section{BAPCs effectively deliver lethal dsRNAs added to the solid diet of Tribolium castaneum}

Tribolium castaneum (the red flour beetle) has become a prominent model organism. The insect's diet in nature is broken kernels of cereals, especially wheat. In the laboratory, Tribolium is typically maintained on wheat flour supplemented (at $5 \% \mathrm{w} / \mathrm{w}$ ) with yeast extract.

The standard method of delivering dsRNA to Tribolium is injection, often in larvae. The advantage of delivering dsRNA through diet rather than by injection is clear. Figure 5 shows experiments with dsRNAs targeted at two components of the Unfolded Protein Response, namely BiP (GRP78) ${ }^{20}$ and Armet (MANF) ${ }^{22}$. As shown in the survival curves of Figure 5, Tribolium is effectively killed by ingestion (by larvae) of a combination of BiP-dsRNA and Armet-dsRNA as dsRNA/ BAPC complexes. These deaths ( $75 \%$ of the subjects, $\mathrm{n}=30$ ) occurred in larvae or during eclosion (the emergence of adults from pupae). For those insects treated with dsRNAs alone their survival curves did not differ significantly from those with no additions to the diet (water alone). Larval/pupal deaths induced with the ingestion of the two dsRNA/BAPC complexes were significantly greater compared to the ingestion of either BiP-dsRNA or Armet-dsRNA complexed with BAPCs (50\% and 40\%, respectively -- results not shown for Armet-dsRNA/BACPs). In another experiment, there were no deaths observed when these complexes were fed to adult insects. In larvae, the process of molting leads to reorganization of the barrier peritrophic membrane (PM) that lines the midgut. Since the insects are fed over several days that include more than one molt, this reorganization would occur. We believe that our complexes could penetrate deeper into tissues during this period thus permitting the systemic delivery of dsRNA-BAPCs. Since this process does not occur in adults, having an intact barrier could be the reason we see little or no effect of silencing using the oral administration route. In the case of aphids, a less evolved organism, this membrane is not present ${ }^{28}$. Feeding our complexes to these insects is quite effective suggesting that the transcripts that we are targeting are required throughout the life-span of the organism.

Tribolium is well known for the systemic nature of its RNA interference. The Vermillion gene acts in the developing eye with its transcript encoding the protein required for the development of normal eye color ${ }^{29}$. Ingestion of Vermillion-dsRNA in complex with BAPCs requires movement of the complexes (or at least dsRNA released from the complexes) from the gut into the hemolymph. We found that ingestion of the complexes during late larval stages gave rise to adults with white (non-colored) eyes at a rather high frequency (about $50 \%$ with $n=20$ ), thus verifying the systemic nature of the RNAi effect created by ingestion 
of dsRNA/BAPC complexes. Figure 6 shows and example of the white-eyed phenotype induced by the ingestion of dsRNA/BAPCs complexes.

\section{Distribution of the dsRNA in Tribolium internal organs after oral administration with and without complexation.}

In order to study the distribution of dsRNAs in Tribolium, we fed a diet mixed that contained fluorescence labeled Armet-dsRNA for $8 \mathrm{hr}$ before dissection. Fluorescence was found in the midgut epithelial cells, fat bodies, and malpighian tubules, while dsRNA-only controls showed low or no background fluorescence in the equivalent regions (Fig. 7). Intracellular fluorescence was clumped in epithelial cells of midgut (Fig. 7A). The midgut region is the only part of the gut with exposed epithelial cells, and it is the main site of exchange between the circulatory system (hemolymph) and gut contents. Fat bodies also show a significant accumulation of the labeled RNA, within the intracellular large vesicles, presumptive endosomes (Fig. 7B). The fat body is involved in multiple metabolic functions, the equivalent to the liver in larger animals. Malpighian tubule showed strong fluorescence in the single layer cells lining the lumen (Fig. 7C). In arthropods, the malpighian tubules are part of the excretory and osmo-regulatory system, the equivalent to the kidney in higher animals. Presumably, oral RNAi effects in distal tissues is mediated by the exit of dsRNA from the midgut epithelial cells to the hemolymph and then accumulate in the Malpighian tubules and fat bodies ${ }^{30}$. These results represent the first bio-accumulation study of dsRNA associated with nanoparticles ingested from diet in insects. In addition, to the best of our knowledge, oral administration of dsRNA has not been demonstrated in Fat body before.

\section{CONCLUSIONS}

BAPCs provide a simple, chemically defined and controllable means of reliably delivering double-stranded RNA to insects in either solid or liquid diets. Delivery is in the form of dsRNA/BAPC complexes. The biophysical properties of the dsRNA/BAPC complexes are very similar to the BAPCs-DNA complexes previously reported ${ }^{3}$. BAPCs mixed with dsRNA form compact clusters with sizes ranging predominantly from 70 to $500 \mathrm{~nm}$ and with zeta potentials ranging from 10 to $18 \mathrm{mV}$. AFM was also used to confirm the topologies of the BAPC-dsRNA complexes. Compact clusters were seen suggesting that the nucleic acids appeared to surround the cationic surface of the peptide capsules. These results indicate that BAPCs may dramatically stabilize dsRNA and confer protection against degradation, while enhancing their uptake by gut epithelial cells. Furthermore, in vivo tissue distribution studies of the dsRNA-BAPCs complexes, shows that the dsRNA, only when complexed with BAPCs, is able to escape the gut and accumulate in distal regions of the body.

To date we have generated knockdowns in proteins involved in the UPR in flour beetle (Tribolium castaneum) larvae and adult pea aphids (Acyrthosiphon pisum). The unfolded protein response (UPR) is activated in response to an accumulation of misfolded proteins in the lumen of the endoplasmic reticulum. Proteins involved in the UPR restore normal function of the endoplasmic reticulum. Suppressing their active in gut epithelium cells can induce apoptosis interfering with the absorption of nutrients in insects ${ }^{31}$. These results observed in two different insects, from two Orders, suggest that our approach could be 
widely applicable in other insects. Furthermore, these complexes should allow for RNAibased transcript knockdown experiments in insect species which are too small for injection in the laboratory (including small aphid species such as the Russian Wheat Aphid or green bug) as well as field applications including the intentional killing or lessening of life-span and fecundity of insect pests of plants, animals and humans such as the virus-transmitting mosquitos, fleas, and ticks.

\section{Supplementary Material}

Refer to Web version on PubMed Central for supplementary material.

\section{Acknowledgements:}

This is publication 17-191-J from the Kansas Agricultural Experiment Station. Partial support for this project was provided by the Terry Johnson Cancer Center at Kansas State University and by the USDA's National Institute of Food and Agriculture through the Specialty Crops Research Initiative/Citrus Disease Research \& Extension, USDA NIFA Award No. 2015-70016-23028. We acknowledge Benjamin Schoenek for his contribution on the AFM analysis.

\section{REFERENCES}

1. Gudlur S, Sukthankar P, Gao J, Avila LA, Hiromasa Y, Chen J, Iwamoto T, Tomich JM, Peptide nanovesicles formed by the self-assembly of branched amphiphilic peptides, PLOS ONE. 7 (2012) e45374.

2. Barros SM, Whitaker SK, Sukthankar P, Avila LA, Gudlur S, Warner M, Beltrão EIC, Tomich JM, A Review of Solute Encapsulating Nanoparticles used as Delivery Systems with Emphasis on Branched Amphipathic Peptide Capsules. Arch Biochem Biophys. 596 (2016) 22-42. [PubMed: 26926258]

3. Avila LA, Aps LMMM, Sukthankar P, Ploscariu N, Games PD, Whitaker SK, Fang Y, Szoszkiewicz R, Ferreira LCS, Tomich JM, Branched amphiphilic cationic oligo-peptides for delivery of plasmid DNA vaccines. J. Control Release. 241 (2016) 15-24. [PubMed: 27592740]

4. Sukthankar P, Gudlur S, Avila LA, Whitaker SK, Katz BB, Hiromasa Y, Gao J, Thapa P, Moore D, Iwamoto T, Chen J, Tomich JM, Branched oligopeptides form nano-capsules with lipid vesicle characteristics. Langmuir 29 (2013) 14648-54. [PubMed: 24188529]

5. Sukthankar P, Whitaker SK, Garcia M, Herrera A, Boatwright M, Prakash O, Tomich JM. Thermally induced conformational transitions in nascent branched amphiphilic peptide capsules. Langmuir 31 (2015) 2946-55. [PubMed: 25719598]

6. Barros SM, Avila LA, Whitaker SK, Sukthankar P, Beltrão EIC, Tomich JM, Branched Amphipathic Peptide Capsules: Different Ratios of the Two Constituent Peptides Direct Distinct Bilayer Structures and Sizes. Langmuir. 33 (2017) 7096-7104. [PubMed: 28654272]

7. L Jackson A, Bartz SR, Schelter J, Kobayashi SV, Burchard J, Mao M, Li B, Cavet G, Linsley PS, Expression profiling reveals off-target gene regulation by RNAi Nature Biotechnology. 21 (2003) 635-637.

8. Whitehead KA, Langer R, Anderson DG, Knocking down barriers: advances in siRNA delivery. Nat. Rev. Drug Discovery 8 (2009) 129-138. [PubMed: 19180106]

9. Terenius O, Papanicolaou A, Garbutt JS, Eleftherianos I, Huvenne H, Kanginakudru S, et al. RNA interference in Lepidoptera: An overview of successful and unsuccessful studies and imply. cations for experimental design. J. Insect Physiol. 27 (2011) 231-245.

10. Yu N, Christiaens O, Liu J, Niu J, Cappelle K, Caccia S, Huvenne H, Smagghe G, Delivery of dsRNA for RNAi in insects: an overview and future directions. Insect Sci. 20 (2013) 4-14. [PubMed: 23955821]

11. Huvenne H, Smagghe G, Mechanisms of dsRNA uptake in insects and potential of RNAi for pest control, a review. J. Insect Physiol. 56 (2010) 227-235. [PubMed: 19837076] 
12. Zhang X, Zhang J, Zhu KY. Chitosan/double-stranded RNA nanoparticle mediated RNA interference to silence chitin synthase genes through larval feeding in the African malaria mosquito (Anopheles gambiae). Insect. Mol. Biol. 19 (2010) 683-693. [PubMed: 20629775]

13. Cancino-Rodezno A, Alexander C, Villaseñor R, Pancheco S, Porta H, Pauchet Y, Soberón M, Gill SJ, Bravo A. The mitogen activated protein kinase p38 is involved in insect defense against Cry toxins from Bacillus thuringiensis. Insect Biochem. Mol. Biol. 40 (2010) 58-63. [PubMed: 20040372]

14. Whyard S, Singh AD, Wong S, Ingested double-stranded RNAs can act as species specific insecticides. Insect Biochem. Mol. Biol. 39 (2009) 824-832. [PubMed: 19815067]

15. Richards S, Gibbs RA, Weinstock GM, Brown SJ, Denell R, The genome of the model beetle and pest Tribolium castaneum. Nature 452 (2008) 949-955. (International Genomics Consortium) [PubMed: 18362917]

16. The International Aphid Genomics Consortium. Plos ONE, 2010, 8, e1000313

17. Miller SC, Miyata K, Brown SJ, Tomoyasu Y, Dissecting Systemic RNA Interference in the Red Flour Beetle Tribolium castaneum: Parameters Affecting the Efficiency of RNAi. PLoS One. 7 (2012) e47431.

18. Jarvis DL, Oker-Blom C, Summers MD, Role of glycosylation in the transport of recombinant glycoproteins through the secretory pathway of lepidopteran insect cells. J. Cell. Biochem. 42 (1990) 181-191. [PubMed: 2341487]

19. Wang W, Dai H, Zhang Y, Chandrasekar R, Luo L, Hiromasa Y, Sheng C, Peng G, Chen S, Tomich JM, Reese J, Edwards O, Kang L, Reeck G, Cui F, Armet is an effector protein mediating aphidplant interactions. FASEB J. 29 (2015) 2032-2045. [PubMed: 25678626]

20. Lorenzen MD, Brown SJ, Denell RE, Beeman RW, Cloning and Characterization of the Tribolium castaneum Eye-Color Genes Encoding Tryptophan Oxygenase and Kynurenine 3-Monooxygenase. Genetics. 160 (2002) 225-34. [PubMed: 11805058]

21. Mutti NS, Louis J, Pappan LK, Pappan K, Begum K, Chen MS, Park Y, Dittmer N, Marshall J, Reese JC, Reeck GR, A protein from the salivary glands of the pea aphid, Acyrthosiphon pisum, is essential in feeding on a host plant. Proc. Natl. Acad. Sci. 29 (2008) 9965-9969.

22. Beeman RW, Stuart JJ, A gene for lindane+cyclodiene resistance in the red flour beetle (Coleoptera, Tenebrionidae). J. Econ. Entomol. 83 (1990) 1745-1751.

23. Tomoyasu Y, Denell RE, Larval RNAi in Tribolium (Coleoptera) for analyzing adult development. Dev. Genes Evol. 11 (2004) 575-578.

24. Akey DH, Beck SD, Continuous Rearing of the Pea Aphid, Acyrthosiphon pisum, on a Holidic Diet. Ann. Entomol. Soc. Am. 2 (1971) 353-356.

25. Honary S, Zahir F, Effect of zeta potential on the properties of nano-drug delivery Systems. Trop. J. Pharm. Res. 2 (2013) 265-273.

26. Yamamoto Y, Nagasaki Y, Kato Y, Sugiyama Y, Kataok K, Long-circulating poly(ethylene glycol)poly(D,L-lactide) block copolymer micelles with modulated surface charge, J. Controlled Release. 77 (2001) 27-39.

27. Cohen AC, Solid-to-Liquid Feeding: The Inside(s) Story of Extra-Oral Digestion in Predaceous Arthropoda. Am. Entomol. 44 (1998) 103-117.

28. P Silva C, R Silva J, F Vasconcelos F, A Petretski MD, A DaMatta R, F Ribeiro A, R Terra W. Occurrence of midgut perimicrovillar membranes in paraneopteran insect orders with comments on their function and evolutionary significance, Arthropod. Struct. Dev. 33 (2004) 139-148.

29. White LD, Coates DJ, Atkinson PW, O'Brochta DA An eye color gene for the detection of transgenic non-drosophilid insects. Insect Biochem. Mol. Biol. 26 (1996) 641-644. [PubMed: 8995786]

30. Price DRG, Gatehouse JA. RNAi-mediated crop protection against insects. Trends Biotechnol. 26 (2008) 393-400. [PubMed: 18501983]

31. Bernales S, Papa FR, Walter P, Intracellular signaling by the unfolded protein response. Annu. Rev. Cell Dev. Biol. 22 (2006) 487-508. [PubMed: 16822172] 
A
B

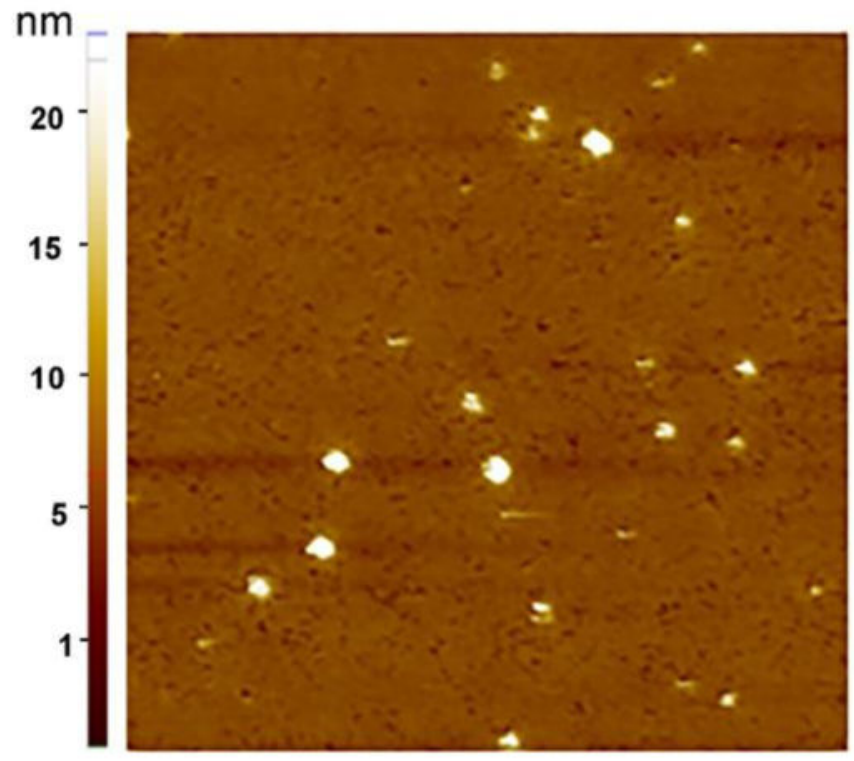

$\mathrm{nm}$

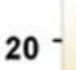

15

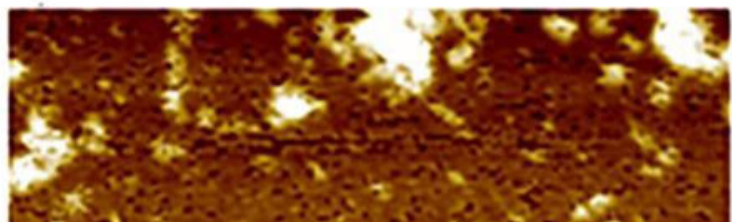

10

5

1

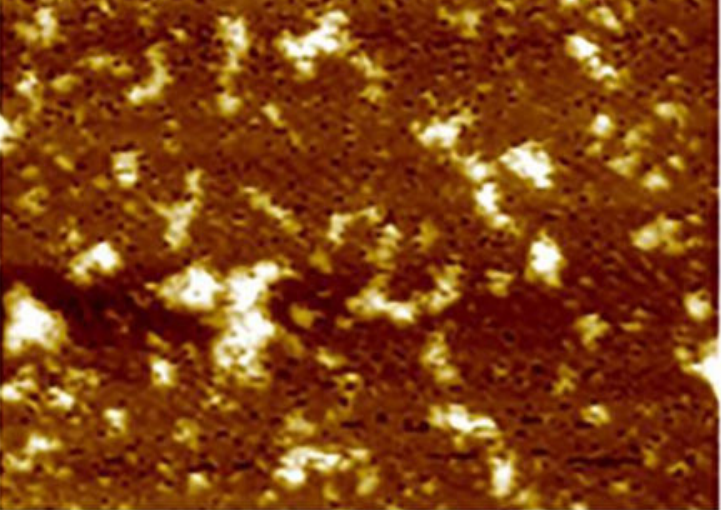

C

+dsRNA
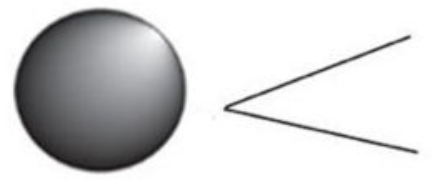

Only BAPCs

Figure 1.

(A) $5 \times 5 \mu \mathrm{m}$ AFM image analysis of the BACP nanoparticles $(40 \mu \mathrm{M})$. (B) $5 \times 5 \mu \mathrm{m}$ AFM image analysis of the BACP- dsRNA complexes ( $40 \mu \mathrm{M}$ and $1 \mu \mathrm{g}$ respectively) $(\mathbf{C})$ Schematic representation of BACPs- dsRNA interactions. 

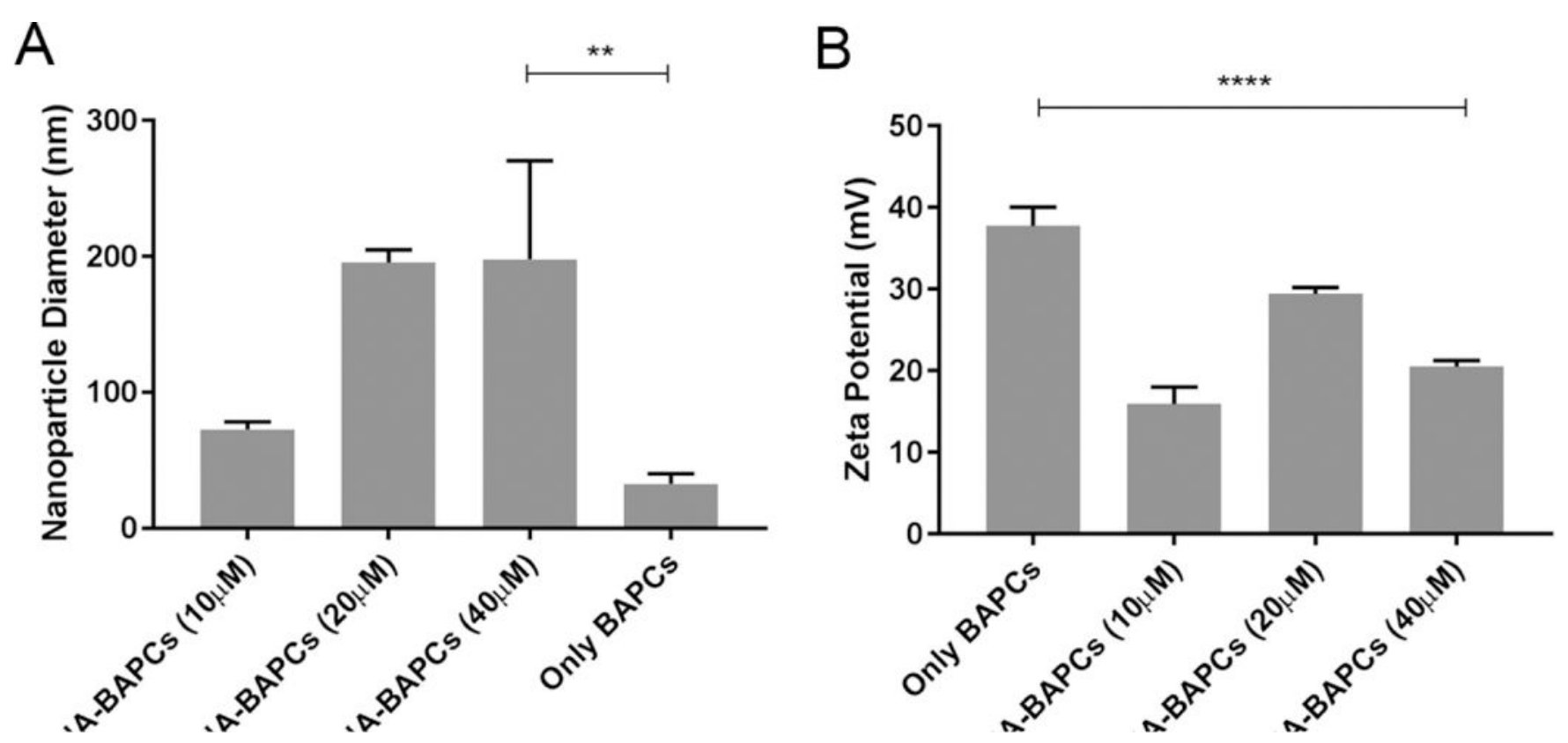

Figure 2. (DLS) and (ZP) analyses for different BAPCs-DNA formulations.

(A) Size (z-average) and (B) zeta potential. Data are based on two independent experiments.

Different formulations were tested keeping the amount of dsRNA constant ( $1 \mu \mathrm{g})$ and varying the BACPs concentration. Differences between values were compared by ANOVA using Bonferroni as post-test. Statistical significance: $(* *) \mathrm{P}<0.01$; (****) $\mathrm{P}<0.0001$.

Non-statistical significance (ns) was considered when $\mathrm{P}>0.05$. 

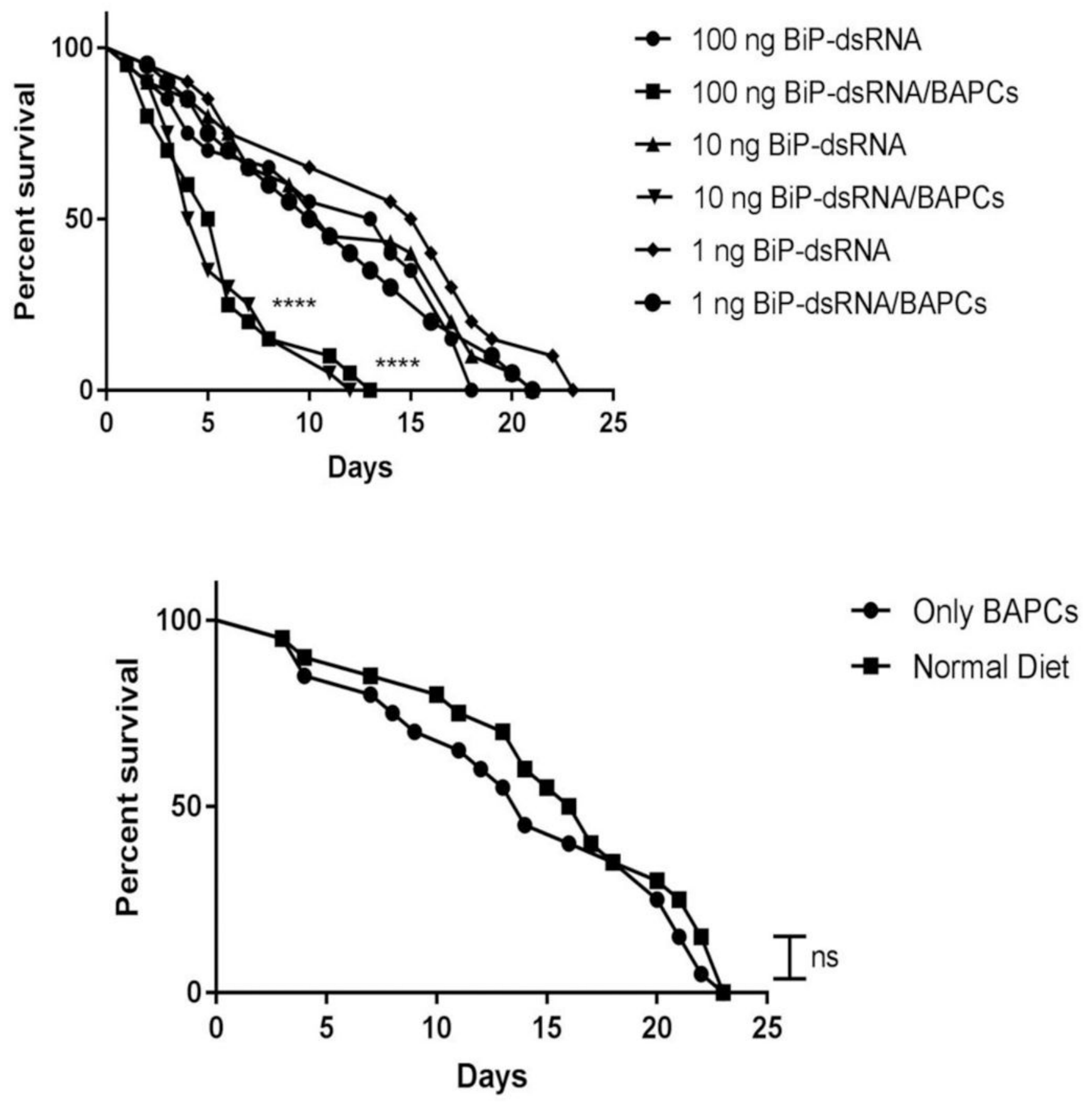

Figure 3. Survival curves showing the effect of BAPCs complexed with BiP-dsRNA in Acyrthosiphon pisum.

The upper panel shows the survival rates for dsRNA at the indicated concentrations plus and minus the BAPCs. The bottom panel represents the RNA-free diet without and without BAPCs. Data is based on three independent experiments, $\mathrm{n}=20$ for each experiment. Statistical significance: $(* * * *) \mathrm{p}<0.0001$ versus control groups treated with naked BiPdsRNA. Non-statistical significance (ns) was considered when $\mathrm{p}>0.05$. Differences between values were compared by Log-rank (Mentel-Cox) test. 


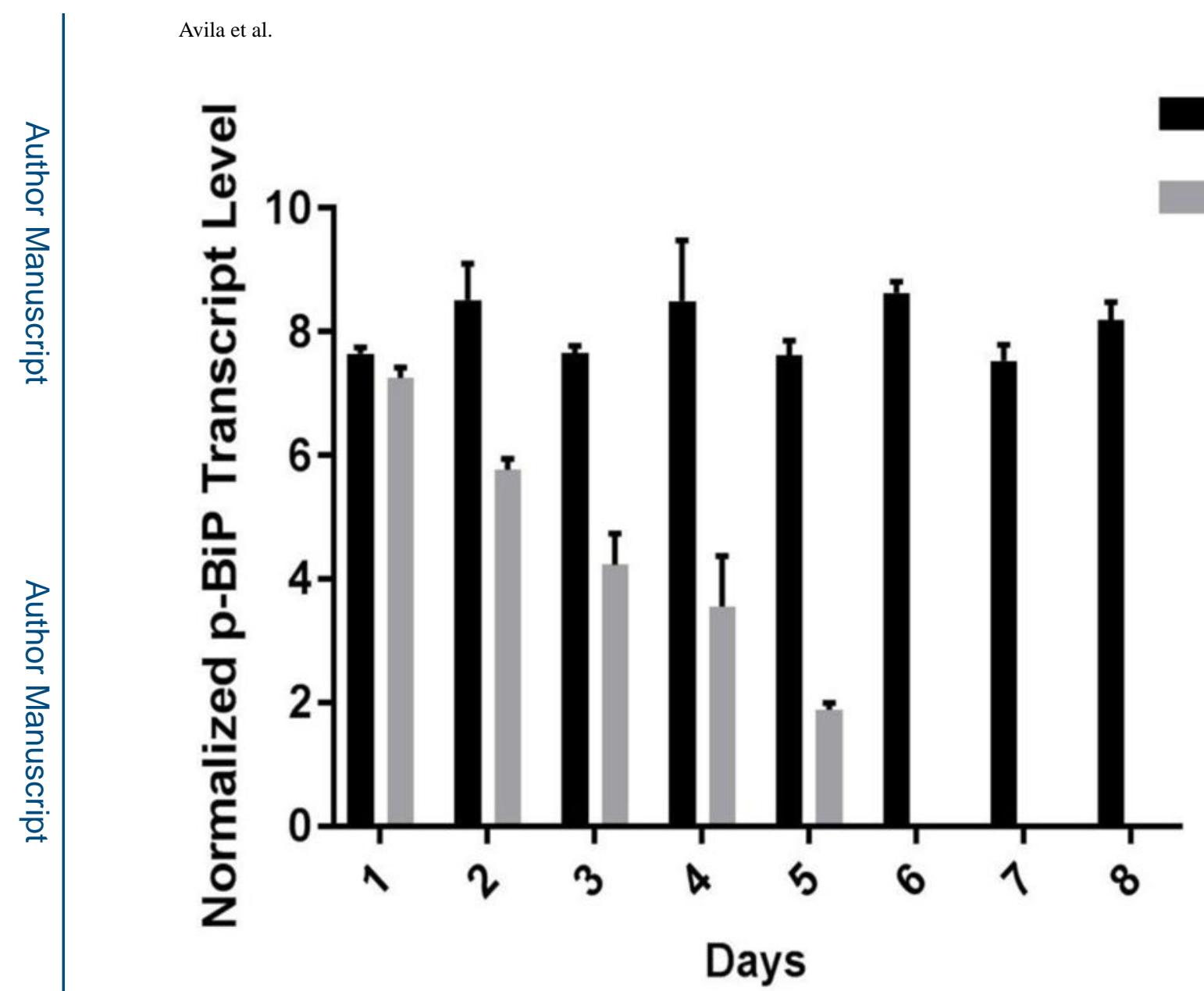

Figure 4:

Pea aphid transcript levels of BIP-mRNA isolated from gut. Shown are the transcript levels of the BiP-mRNA when the insects ( $n=20$ per group) were fed BiP-dsRNA with and without complexation with BAPCs. Time zero represents the mRNA levels of insects prior to placing them on the diet. Data represent mean values $+\mathrm{SD}$ of three experiments combined. 


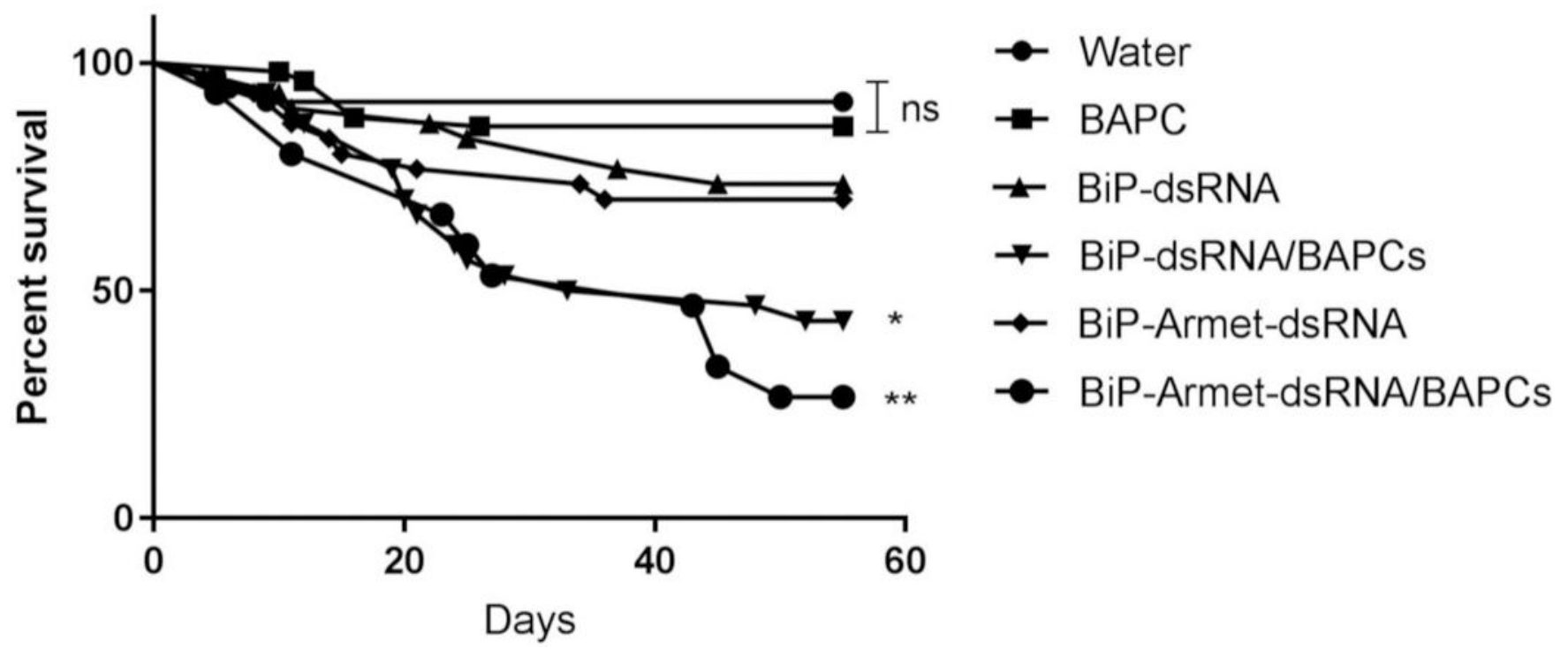

Figure 5. Survival curves showing the effect of BAPCs complexed with dsArmet + BiP-dsRNA in Tribolium castaneum.

Early-instar larvae were fed wheat-flour/yeast extract diet supplemented with Armet- or BiP-dsRNA singly or together (500 ng of each) with or without BAPCs. Day 1 represents the first day of feeding. After 6 days, the insects were transferred to the standard diet, lacking dsRNA or BAPC additions. Diseased Tribolium were counted on a daily basis. The number of insects on Day 1 were 35 (Diet alone); 30 (water plus $\mathrm{CaCl}_{2}$ ) 50 (BAPCs-only control); 30 (Armet-dsRNA alone); 30 (BiP-dsRNA alone); 30 (BIP-dsRNA/BAPC complexes); 30 (BIP- + Armet-dsRNAs/BAPC complexes) and 45 (no BAPCs and no dsRNA). Pupation started over a range of days, averaging about day 30 with eclosion (emergence of adults from pupae) over a range starting about Day 40. No deaths occurred in the adult stage. Statistical significance: $(*) \mathrm{p}<0.05,(* *) \mathrm{p}<0.01$, versus control groups treated with naked BiP-dsRNA or BiP-Armet-dsRNA. Non-statistical significance (ns) was considered when $\mathrm{p}>0.05$. Differences between values were compared by Log-rank (MentelCox) test. 

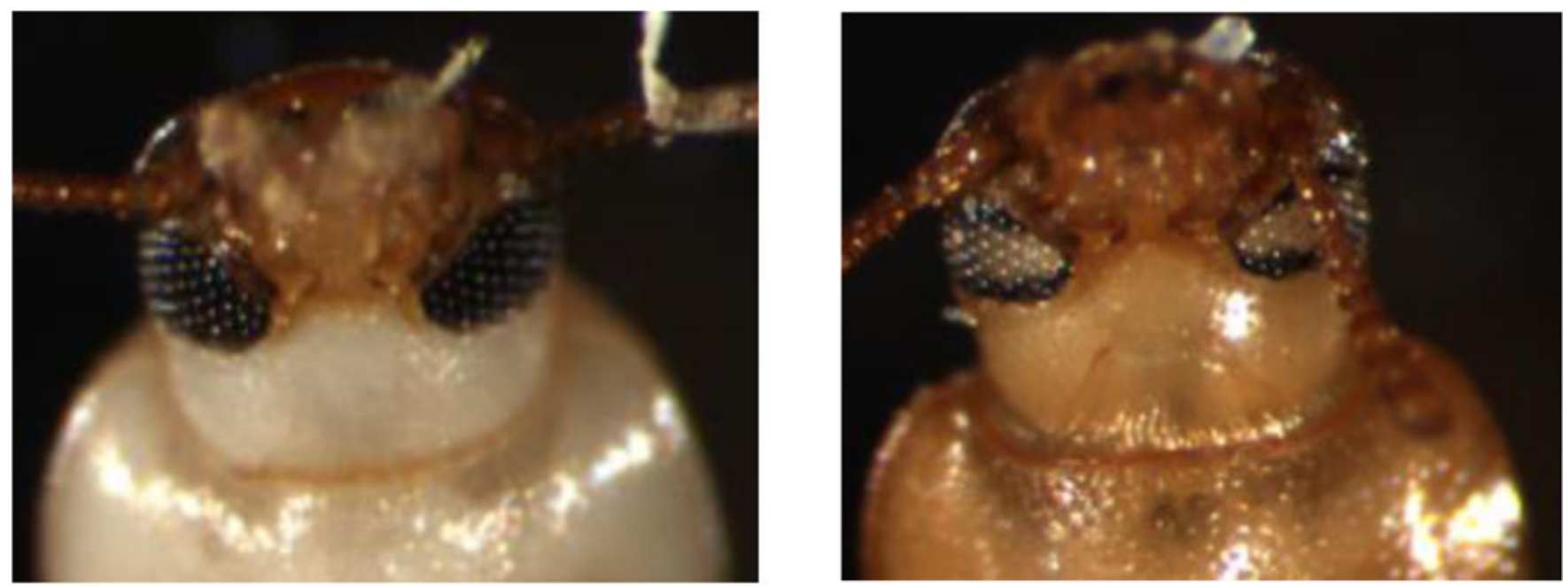

Figure 6. Effects of feeding dsVermillion-RNA -/+ BAPCs in Tribolium.

Feeding of BAPCs-dsVermillion complexes (as a "supplement" to the flour diet of Tribolium larvae) resulted in the absence of Vermillion color (in the eye) in treated insects, right panel. 

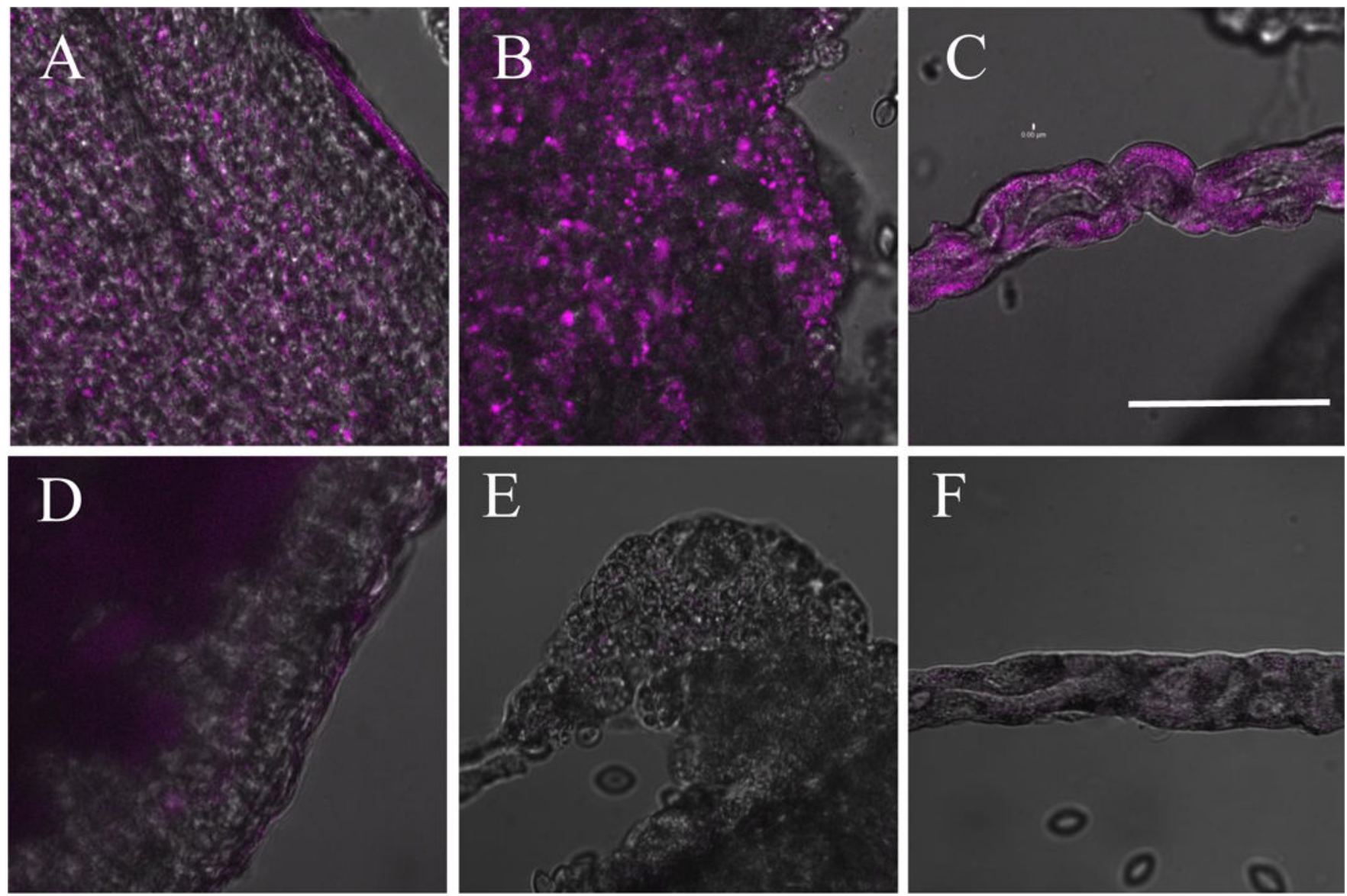

Figure 7. Localization of fluorescently labeled Armet-dsRNA in Tribolium larvae $8 \mathrm{hr}$ after the feeding.

The fluorescence was shown as magenta on the bright-field background. All pictures were captured in the same condition in a LSM700 confocal microscope. (A) midgut; (B) Fat body (C) Malpighian tubule, (D) to (F) are same tissues in the Tribolium fed with labeled ArmetdsRNA alone. Scale bar: $20 \mu \mathrm{M}$ 